\title{
MACROECONOMIC EFFECTS OF TERMS OF TRADE FLUCTUATIONS IN COMMODITY EXPORTING ADVANCED ECONOMIES
}

\author{
Anthony J. Makin* \\ Economics, Griffith Business School \\ Griffith University \\ Gold Coast, 4222 \\ Australia \\ t.makin@griffith.edu.au \\ Nicholas Rohde \\ Economics, Griffith Business School \\ Griffith University \\ Gold Coast, 4222 \\ Australia
}

April 2012 


\title{
MACROECONOMIC EFFECTS OF TERMS OF TRADE FLUCTUATIONS IN COMMODITY EXPORTING ADVANCED ECONOMIES
}

\begin{abstract}
The paper presents an alternative framework for analysing the impact of world commodity prices on national output, expenditure and trade balances in commodity exporting economies. What differentiates this approach from the standard Dutch disease approach to commodity price fluctuations is its explicit focus on the relative price effects of changes in the terms of trade (ToT) on national output and expenditure, rather than centre on real exchange rate implications. With application to the major commodity exporting advanced economies (Australia, Canada, New Zealand and Norway), empirical estimates generally verify the major predictions of the approach that ToT fluctuations should (i) have no significant short run impact on GDP and that (ii) there is unlikely to be a strong positive relationship between ToT and net exports in these economies due to relative price effects.
\end{abstract}

Keywords: terms of trade, commodity exporting advanced economies, national output, trade balance

\section{Contents}

1. Introduction

2. The Terms of Trade, Output and the Trade Balance

3. The Terms of Trade, Output and Trade Balances in CEAEs: Data Issues

4. Testing the Relationship between the Terms of Trade and GDP

5. Testing the Relationship between the Terms of Trade and Net Exports

6. Conclusion 


\section{MACROECONOMIC EFFECTS OF TERMS OF TRADE FLUCTUATIONS IN COMMODITY EXPORTING ADVANCED ECONOMIES}

\section{Introduction}

According to broad based commodity price indices, commodity prices in real terms have boomed since the turn of the century, except for a brief hiatus during the 200809 global financial crisis. Bolstered by strong demand for agricultural and mineral commodities in fast growing Asian economies, most notably China and India, and heightened liquidity levels stemming from monetary expansions engineered by central banks in advanced economies, commodity prices have reached levels comparable to previous historical peaks reached in the 1970s (IMF 2012). Elevated world commodity prices have caused major variation in many economies' terms of trade, measured as the ratio of prices received for commodity exports to prices paid for imports, mainly manufactured goods.

Developing and emerging economies in Asia, Africa and Latin America are generally perceived to be more dependent on exports of commodities than advanced economies and hence more prone to volatile terms of trade (ToT). ${ }^{1}$ However, if an economy's dependence on commodity exports is measured as the proportion of commodity exports in its total exports, it so happens that a select group of advanced economies Australia, Canada, New Zealand and Norway - are more heavily reliant on commodity exports than many developing commodity exporters in Asia and Latin America (IMF 2012). Indeed, after declining slightly for three decades, commodity exporting advanced economies (CEAEs) increased their dependence on commodity exports significantly from 2000, with their commodity exports reaching an average of sixty per cent of total exports in 2010 (Adler and Sosa 2011).

An extensive literature on the macroeconomics of commodity price fluctuations has explored numerous dimensions. For instance, from the mid-1970s many authors examined how real exchange rate appreciation could cause de-industrialisation in the context of rising world energy prices and resource discoveries, the so-called Dutch

\footnotetext{
${ }^{1}$ A related literature examines whether developing economies' reliance on commodity exports stymies economic development via the "resources curse" (see Lederman and Maloney 2007, van der Ploeg 2011, Frankel 2012).
} 
disease theory based on the dichotomy between tradables and non-tradables (see, for instance, McKinnon 1976, Snape 1977, Stoeckel 1979, Forsyth and Kay 1980, Corden and Neary 1982, Bruno and Sachs 1982, Buiter and Purvis 1983, Enders and Herberg 1983, Haberger 1983, Corden 1984, and van Wijnbergen 1984).

According to Dutch disease theory, as an economy's export commodity prices boom or as newly found resources are exploited, the real exchange rate appreciates due to a stronger nominal exchange rate, as well as to higher non-tradables prices that stem from a wealth-induced excess demand for non-tradables. In turn, this worsens the international competitiveness of the economy's traditional tradable industries, most notably in the manufacturing sector and can also lead to a trade deficit. More recent work on the macroeconomic consequences of commodity price rises have focused on their implications for inflation (IMF 2011) and on fiscal effects (see Lespedes and Velasco 2011, Kaminsky 2009).

This paper contributes to the literature in two ways. First, unlike the Dutch disease approach which seeks to explain the macroeconomic effects of commodity price fluctuations via real exchange rate variation, it focuses on linkages between the terms of trade, national output and trade balances. Second, it empirically tests the implications of this alternative perspective with particular reference to the experience of the major CEAEs - Australia, Canada, New Zealand and Norway.

The next section proposes a straightforward theoretical framework for interpreting the impact of ToT variations on key macroeconomic variables in the short term. This approach suggests the ToT are unlikely to affect national output, but will alter export and import volumes due to the income and substitution effects associated with relative price changes. Section 3 examines the properties of the key data series for Australia, Canada, New Zealand and Norway. Sections 4 and 5 respectively test the relationships between the ToT and national output, and the ToT and net exports, for each of these economies. Section 6 concludes the paper.

\section{The Terms of Trade, National Output and the Trade Balance}

This section presents a new framework to interpret the impact of terms of trade changes on an economy's output, expenditure and the trade balance in the short run. 
Combining dual distinctions, that between exportables and importables, and that between output and expenditure, this approach infers two testable hypotheses. These are that in commodity exporting countries (i) the ToT do not significantly affect GDP since production inputs are given in the short run, and (ii) the ToT do not significantly influence net exports, since increased exports are offset by increased imports due to the income and substitution effects of a relative price change.

In this framework goods and services are either exportables $(\chi)$ or importables $(v)$. Exportables are predominately agricultural and mineral commodities, whereas importables are mainly manufactures. A production possibility frontier conveys real Gross Domestic Product, the combined output of exportables and importables, on the supply side of the economy, as in Figure 1. Output of exportables and importables is produced using sector-specific capital stocks at fixed levels, and capital is immobile between the two sectors in the short run.

The total labor force is also given, but can shift between the two sectors endogenously. Thus the frontier reveals all possible production combinations of $\chi$ and $v$ that yield a given volume of real GDP. Its concavity reflects diminishing returns as labor moves more and more from $\chi$ into $v$ production. Any point on the transformation curve therefore shows that the more $\chi$ is produced, the less $v$ will be produced since labor shifts to the expanding commodity sector from the other sectors.

The national expenditure or aggregate demand side of the economy is represented by a community indifference curve capturing the spending preferences of resident entities as between $\chi$ and $v$. The convexity of these curves reflects the diminishing marginal rate of substitution between $\chi$ and $v$, and no specific restrictions (homothetic, quasi-homothetic or linear, after Deaton and Muellbauer 1980) need be imposed on demand behaviour.

The foreign currency prices $\chi$ and $v$ set in world markets, and domestic entities can export and import as much as possible of either without affecting the world price received or paid in foreign exchange terms. The nominal exchange rate translates the foreign currency prices of $\chi$ and $v$ into domestic currency values, such that 


$$
\mathrm{T}=\mathrm{eP}_{\chi}^{*} / \mathrm{eP}_{v}^{*}=\mathrm{P}_{\chi} / \mathrm{P}_{v}
$$

where $\mathrm{T}$ is the terms of trade, $\mathrm{P}_{\chi}$ is the price index of exportables in domestic currency, $\mathrm{P}_{v}$ is the price index of importables in domestic currency, and $\mathrm{e}$ is the nominal effective exchange rate. T determines the slope of the line TT in Figure 1 which is tangential to the production possibility and community indifference curves.

In sum, output, $\mathrm{Y}$, of $\chi$ and $v$, and expenditure, $\mathrm{E}$, on $\chi$ and $v$ can be summarised as

$$
\begin{array}{ll}
\mathrm{Y}_{\chi}=\mathrm{f}\left(\stackrel{+}{\mathrm{T}} ; \overline{\mathrm{K}}_{\chi}, \stackrel{+}{\mathrm{L}_{\chi}}\right) & \mathrm{Y}_{v}=\mathrm{g}\left(\stackrel{-}{\mathrm{T}} ; \overline{\mathrm{K}}_{v}, \mathrm{~L}_{v}^{+}\right) \\
\mathrm{E}_{\chi}=\mathrm{f}(\stackrel{+}{\mathrm{T}} ; \stackrel{+}{\mathrm{Y}}) & \mathrm{E}_{v}=\mathrm{g}(\stackrel{+}{\mathrm{T}} ; \stackrel{+}{\mathrm{Y}})
\end{array}
$$

where signs above the arguments of each function indicate the signs of partial derivatives with respect to production or expenditure in the respective sectors.

At initial equilibrium in micro-foundations terms, the marginal rate of transformation of the output of the two sectors, equivalent to the ratio of respective marginal costs of production, equals their marginal rate of substitution on the expenditure side, equivalent to the ratio of marginal utilities of the goods in consumption. That is,

$$
\mathrm{T}=\mathrm{MC}_{\chi} / \mathrm{MC}_{v}=\mathrm{MU}_{\chi} / \mathrm{MU}_{\mathrm{v}}
$$

At point Q in Figure 1, OX exportables are produced and sold, and OM importables are produced and sold. The economy is at full employment on the transformation curve and the balance of trade is zero since exports equal imports. Any other point on the transformation curve implies a trade imbalance, due to either an excess demand or supply of $\chi$ or to an excess demand or supply of $v$.

\subsection{A rise in world commodity prices}

With higher commodity prices, the terms of trade improve which steepens the slope of TT, causing labor to shift into commodity production in the short run from the production of other goods and services. The steeper slope of TT implies that 
increased total expenditure on a higher indifference curve is possible due to an income effect, while a substitution effect implies a shift along the community indifference curve. The change in output relative to expenditure induced by the terms of trade boost also alters the economy's balance of trade. Exportables rise by X, representing the difference between the increased production of commodities and altered domestic absorption of them. Meanwhile, at the new relative price, importables rise to $\mathrm{M}$, representing the difference between the increased demand for importables and their reduced production.

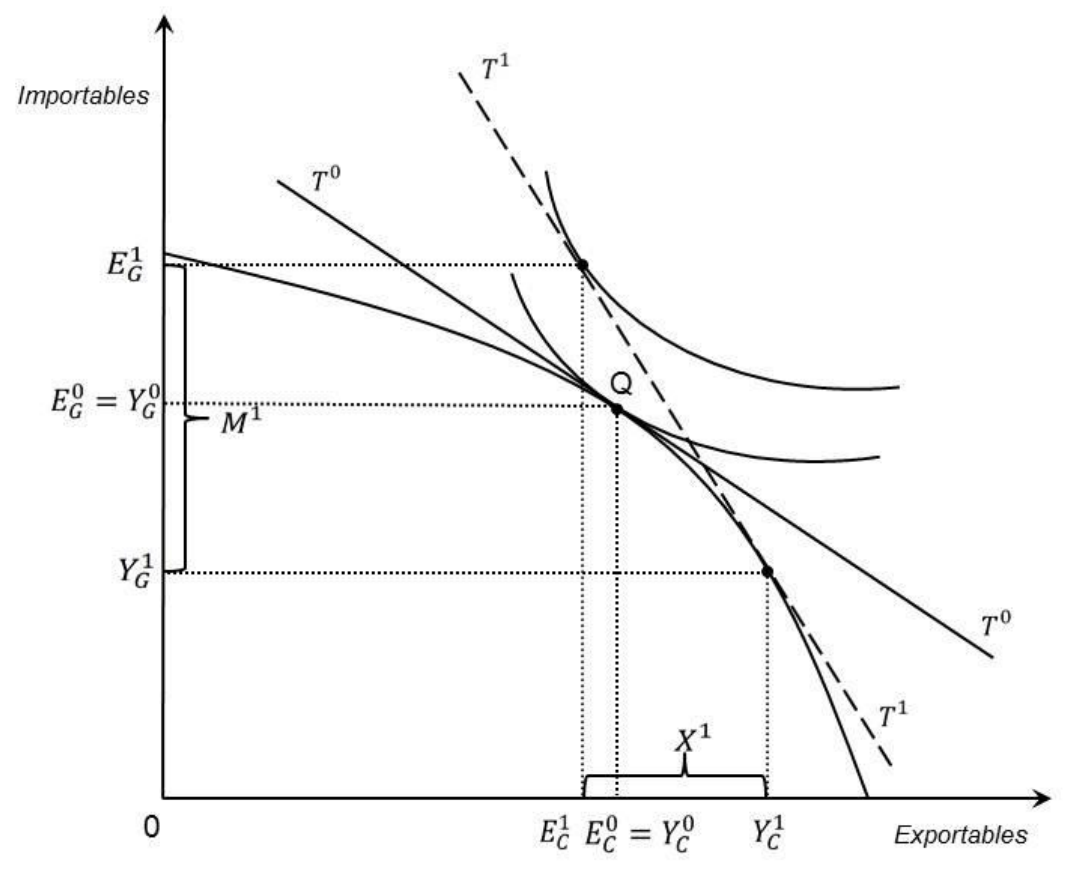

Figure 1. Improved Tof T, National Output and the Trade Balance

In sum, this analysis shows that, given available factor inputs, a commodity price rise alters the composition but not volume of real GDP. Hence, it implies that international commodity price rises do not, of themselves, increase economic growth in the short run, but do raise total expenditure in the economy via a windfall income effect which raises the economy's international purchasing power. At the same time, the relative price change boosts commodity exports and imports of other goods and services. 
Interestingly, since the income effect of the ToT improvement increases spending on $\chi$ and $v$, and hence imports, the impact of the ToT on the trade balance is ambiguous a priori. This runs counter to the expectation that higher commodity prices and increased commodity production for export would significantly increase net exports by boosting exports.

\section{The Terms of Trade, Output and Trade Balances in CEAEs: Data Issues}

Before testing the hypotheses formulated in the previous section 2 we examine the properties of the Terms of Trade (ToT) and Gross Domestic Product (GDP) and Trade Balance (TB) data for Australia, New Zealand, Canada and Norway. This data was sourced from International Monetary Fund International Financial Statistics database and consists of quarterly observations on all three variables from Q1 1980 to Q3 2011, although some early observations are unavailable for New Zealand.

Real GDP for the four countries is plotted in Figure 1 where the first observation is indexed at 100. The plot shows high growth in Australia and New Zealand over the time period with lower growth in Canada and Norway. Figure 2 shows the ToT for these countries. While the plots for all four countries are reasonably volatile, there is a notable upward trend in all cases starting around 2000 coinciding with increased commodity prices at this time. This is particularly evident in Norwegian and Australian data. Figure 3 shows the corresponding plots for each country's TB as a percentage of GDP, where a positive value indicates a surplus and a negative score implies a deficit. 
Figure 1. Real GDP for Australia, Canada, New Zealand and Norway, 1980-2011

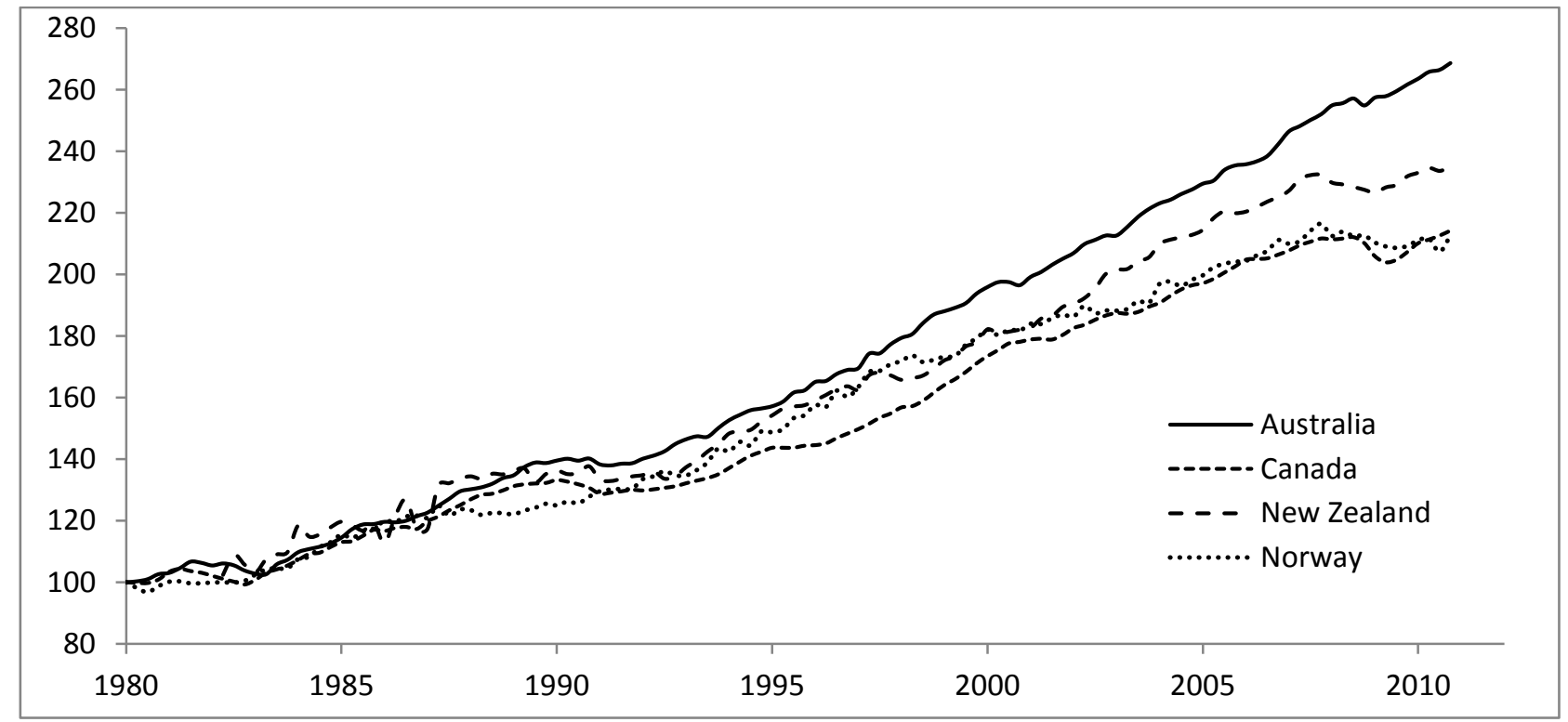

Note: GDP (vertical axis) is depicted with an index normalized at 100 in Q1 1980.

Figure 2. ToT for Australia, Canada, New Zealand and Norway 1980-2011

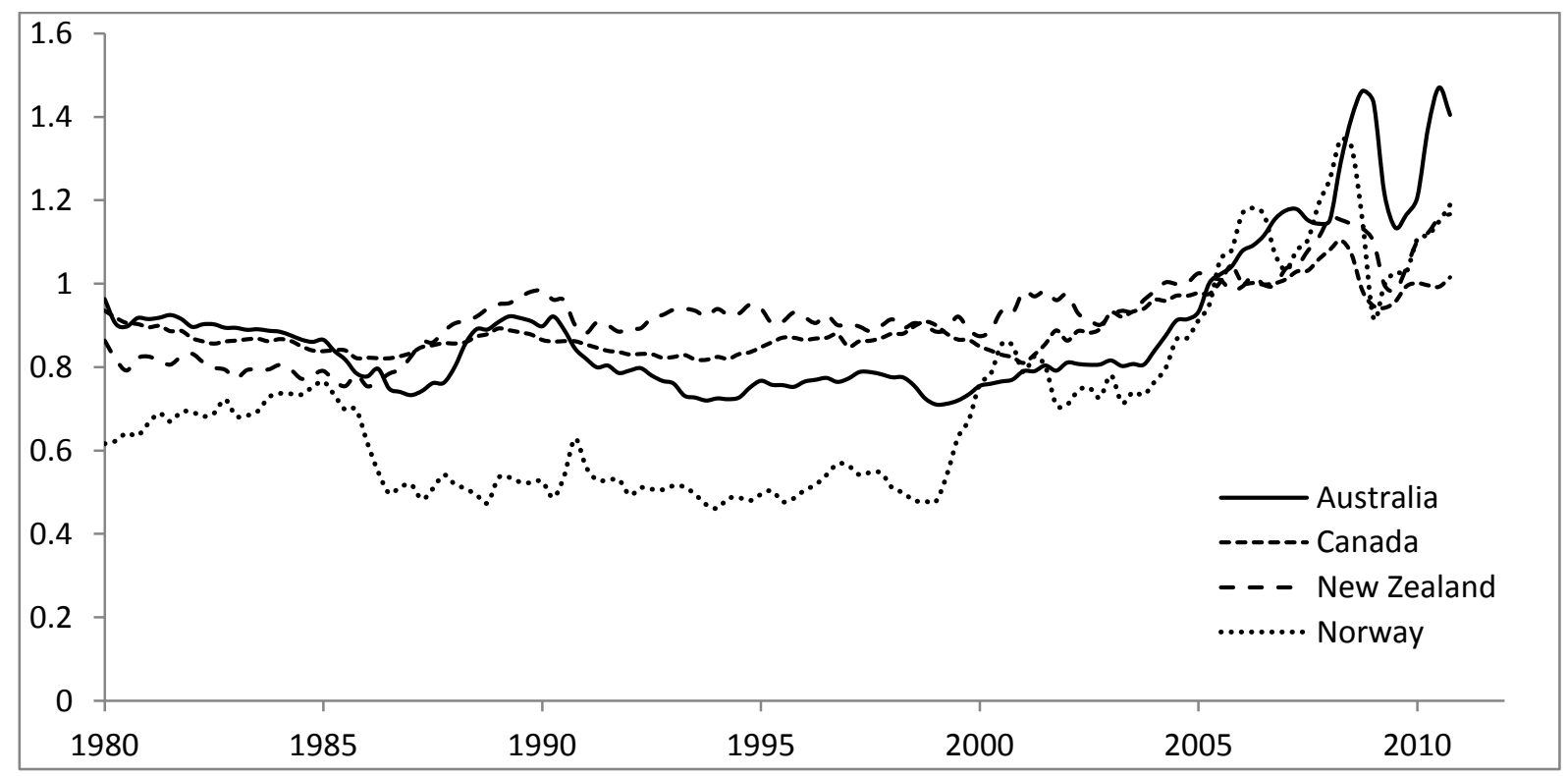

Note: ToT (vertical axis) is the ratio of export to import prices. 
Figure 3. TB (\% GDP) for Australia, Canada, New Zealand and Norway 19802011

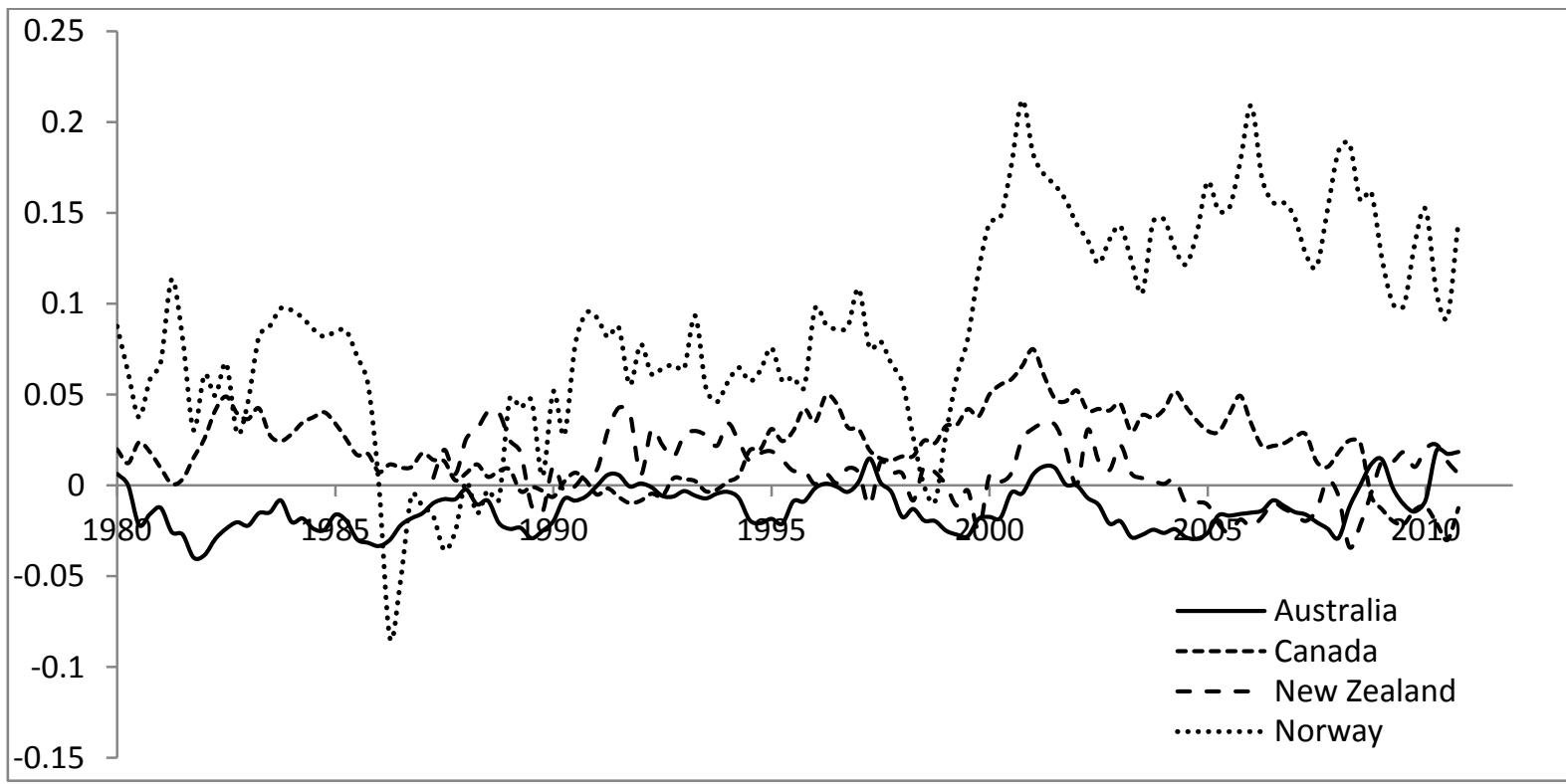

To examine the dynamic relationships between these variables we initially consider their timeseries properties. Unit root tests of the ADF form are employed where lag length $m$ is selected on the basis of the Akaike Information Criterion. The test equation is

$$
\Delta x_{t}=\alpha+\gamma t+(1-\theta) x_{t-1}+\sum_{s=1}^{m} \phi_{s} \Delta x_{t-1}+\varepsilon_{t}
$$

For the sake of robustness we augment these results with DF-GLS unit root tests which use a Generalized Least Squares process for de-trending residuals and PhillipsPerron tests which employs a non-parametric method for correcting for autocorrelation in the residuals. All three test equations are applied to each variable, both in levels and differences and the results are reported in Tables 1 to 3. 
Table 1. Unit root tests on GDP and $\triangle G D P$ for CEAEs

\begin{tabular}{l|llll|lllll|lll}
\hline \hline & $\tau$ & \multicolumn{3}{|l}{$G D P$} & & & $\tau$ & $\Delta G D P$ & & & \multicolumn{2}{l}{ Critical } \\
\hline Test & Aust & Can & NZ & Nor & Aust & Can & NZ & Nor & $1 \%$ & $5 \%$ & $10 \%$ \\
\hline ADF & -1.80 & -2.32 & -2.25 & -1.40 & -9.49 & -5.40 & -10.8 & -14.4 & -4.03 & -3.45 & -3.15 \\
GLS-ADF & -0.21 & -1.81 & -2.15 & -1.09 & -9.40 & -5.15 & -3.58 & -1.78 & -3.55 & -3.01 & -2.72 \\
PP & -1.80 & -2.09 & -2.04 & -2.26 & -9.53 & -5.33 & -12.4 & -14.0 & -4.03 & -3.45 & -3.15 \\
\hline \hline
\end{tabular}

Test statistics $(\tau)$ for the hypothesis $\theta=1$ are reported for the ADF, ADF-GLS and PP tests. Critical values are given for $1 \%, 5 \%$ and $10 \%$ significance for each test equation in the three right hand columns. Test statistics that are less than the critical value imply rejection of the null hypothesis of non-stationarity.

Table 2. Unit root tests on ToT and $\triangle T$ T T for CEAEs

\begin{tabular}{|c|c|c|c|c|c|c|c|c|c|c|c|}
\hline & $\bar{\tau} \tau$ & ToT & & & $\bar{\tau}$ & $\Delta T o T$ & & & $\tau \quad \mathrm{Cri}$ & & \\
\hline Test & Aust & Can & $\mathrm{NZ}$ & Nor & Aust & Can & $\mathrm{NZ}$ & Nor & $1 \%$ & $5 \%$ & $10 \%$ \\
\hline ADF & -0.41 & -2.66 & -2.86 & -1.87 & -5.56 & -8.33 & -9.22 & -8.32 & -4.03 & -3.45 & -3.15 \\
\hline GLS-ADF & -0.48 & -1.60 & -2.45 & -1.70 & -2.56 & -7.73 & -6.95 & -8.32 & -3.55 & -3.01 & -2.72 \\
\hline PP & 1.12 & -2.52 & -2.88 & -1.63 & -6.06 & -8.02 & -9.20 & -8.03 & -4.03 & -3.45 & -3.15 \\
\hline
\end{tabular}

Test statistics $(\tau)$ for the hypothesis $\theta=1$ are reported for the ADF, ADF-GLS and PP tests. Critical values are given for $1 \%, 5 \%$ and $10 \%$ significance for each test equation in the three right hand columns. Test statistics that are less than the critical value imply rejection of the null hypothesis of non-stationarity.

Table 3. Unit root tests on $T B$ and $\triangle T B$ for CEAEs

\begin{tabular}{l|llll|lllll|lll}
\hline \hline & $\tau$ & \multicolumn{3}{l}{$T B$} & & & \multicolumn{3}{l|}{$\Delta T B$} & & & \multicolumn{3}{l}{ Critical } \\
\hline Test & Aust & Can & NZ & Nor & Aust & Can & NZ & Nor & $1 \%$ & $5 \%$ & $10 \%$ \\
\hline ADF & -4.06 & -1.81 & -4.32 & -3.48 & -9.74 & -10.1 & -12.2 & -10.7 & -4.03 & -3.45 & -3.15 \\
GLS-ADF & -2.85 & -1.93 & -4.00 & -2.89 & -9.25 & -8.62 & -10.3 & -9.23 & -3.55 & -3.01 & -2.72 \\
PP & -3.87 & -1.82 & -4.34 & -3.57 & -10.1 & -10.2 & -12.8 & -10.7 & -4.03 & -3.45 & -3.15 \\
\hline \hline
\end{tabular}

Test statistics $(\tau)$ for the hypothesis $\theta=1$ are reported for the ADF, ADF-GLS and PP tests. Critical values are given for $1 \%, 5 \%$ and $10 \%$ significance for each test equation in the three right hand columns. Test statistics that are less than the critical value imply rejection of the null hypothesis of non-stationarity.

The results from Table 1 indicate that for all tests, we are unable to reject the null of a unit root in the GDP series over the four countries. Performing the tests on the first differences indicates that the GDP series are difference-stationary, with the only exception coming from the DF-GLS test when applied to Norwegian data. For the 
ToT variable in Table 2 we also identify unit roots at all standard significance levels, while the first differences are stationary in all cases except for the DF-GLS test for Australia.

Based upon these results it is concluded that both GDP and ToT are I(1). Conversely when considering TB data we were often able to reject the null of non-stationarity (Table 3) over multiple testing specifications for three of the four countries with the exceptional case of Norway. Given the uniformity of this result across both specifications and countries, and the well recognized low power of the tests, we will regard the trade balance as $\mathrm{I}(0)$.

\section{Testing the Relationship between the ToT and GDP in CEAEs}

As GDP and ToT are I(1) these variables will be modelled in first differences while TB will be considered in levels. A convenient model of short term fluctuations of these stationary variables is Vector Autoregression. Initially we will focus on GDP and ToT where the general model may be written as

$$
\vec{Y}_{t}=\delta+\Theta_{1} \vec{Y}_{t-1}+\cdots+\Theta_{p} \vec{Y}_{t-p}+\vec{\varepsilon}_{t}
$$

where $j=1 \ldots p$ denote lagged terms, each $\Theta_{\mathrm{j}}$ is a $k \times k$ (in our case $2 \times 2$ ) matrix of parameter estimates, $\vec{Y}_{t}$ is a $k$ dimensional vector containing observations on $G D P_{t}$ and $\operatorname{ToT}_{t}$ and $\vec{\varepsilon}_{t}$ is a $k$ dimensional vector of white noise error terms.

Alternatively the specific model can be written as two separate equations of the following expanded form:

$$
\begin{aligned}
\Delta G D P_{t} & =\delta_{1}+\sum_{j=1}^{p} \alpha_{1 j} \Delta G D P_{t-j}+\sum_{j=1}^{p} \beta_{1 j} \Delta T o T_{t-j}+\varepsilon_{1 t} \\
\Delta T o T_{t} & =\delta_{2}+\sum_{j=1}^{p} \alpha_{2 j} \Delta G D P_{t-j}+\sum_{j=1}^{p} \beta_{2 j} \Delta T o T_{t-j}+\varepsilon_{2 t}
\end{aligned}
$$

This VAR model may be estimated using OLS to obtain $\widehat{\Theta}_{1} \ldots \widehat{\Theta}_{p}$ (or equivalently $\hat{\alpha}_{1 j}, \hat{\beta}_{1 j}, \hat{\alpha}_{2 j}$ and $\hat{\beta}_{2 j}$ for $j=1 \ldots p$ ). One critical factor in such an estimation is the 
determination of lag length $p$. There are a number of techniques for selecting the optimal lag length such as Akaike, Schwartz (Bayesian) and Hannan-Quinn Information Criterion.

The notion behind these information measures is to find an optimal trade-off between parsimony and fit. The three indices are

$$
\begin{gathered}
A I C=-2 \frac{l}{T}+2 \frac{k+1}{T} \\
S B C=-2 \frac{l}{T}+(k+1) \times \frac{\ln T}{T} \\
H Q C=-2 \frac{l}{T}+2(k+1) \times \ln \left(\frac{\ln T}{T}\right)
\end{gathered}
$$

where $l$ is the log-likelihood function evaluated at the parameter estimates. Each criterion is decreasing in $l$ and increasing in $k$ and hence the best compromise is obtained with the minimization of each score.

There is little uniformity in optimal lag length however it is felt that for the purpose of cross-national comparisons a fixed length across countries is desirable. Further the problem of including too many lags of wasted degrees-of-freedom is felt to be less serious than the alternative of autocorrelated residuals and for this reason we err on the side of caution and include a constant level of five lags for all countries. Parameter estimates of the specified equations are reported in Table 4.

Results from Table 4 indicate that the ToT variables have little to no significance in explaining future changes in GDP. The equation where a significant lag was recorded was for the initial lag for Canada. Otherwise the variables seem primarily functions of their own histories. 
Table 4. VAR Coefficients for CEAEs, 1980-2011

\begin{tabular}{|c|c|c|c|c|c|c|c|c|}
\hline & \multicolumn{2}{|l|}{ Australia } & \multicolumn{2}{|l|}{ Canada } & \multicolumn{2}{|c|}{ New Zealand } & \multicolumn{2}{|l|}{ Norway } \\
\hline Lag & $\triangle G D P$ & $\Delta T o T$ & $\triangle G D P$ & $\Delta T o T$ & $\triangle G D P$ & $\Delta T o T$ & $\triangle G D P$ & $\Delta T o T$ \\
\hline$\hat{\delta}$ & $0.3453 * * *$ & -0.0089 & $0.1863 * * *$ & -0.0004 & $0.6196 * * *$ & -0.0009 & $0.3786^{* * *}$ & -0.0008 \\
\hline$\hat{\alpha}_{1}$ & $0.1906^{* *}$ & $0.0020 * *$ & $0.6526^{* * *}$ & 0.0010 & -0.0785 & -0.0010 & -0.3039 & -0.0002 \\
\hline$\hat{\alpha}_{2}$ & $0.1931 * *$ & 0.0101 & -0.1280 & -0.0007 & $-0.2653 * * *$ & 0.0031 & 0.1440 & 0.0080 \\
\hline$\hat{\alpha}_{3}$ & -0.0933 & 0.0045 & $0.2685^{* * *}$ & 0.0003 & 0.1609 & $0.0037^{*}$ & 0.0539 & 0.0083 \\
\hline$\hat{\alpha}_{4}$ & -0.1030 & 0.0003 & $-0.2259 * *$ & 0.0033 & 0.0124 & 0.0013 & 0.0753 & 0.0024 \\
\hline$\hat{\alpha}_{5}$ & $0.2281 * * *$ & 0.0037 & 0.0297 & -0.0008 & 0.0275 & 0.0014 & $0.2083^{* *}$ & -0.0074 \\
\hline$\hat{\beta}_{1}$ & 1.5656 & $0.5491 * * *$ & $10.9392 * * *$ & $0.2563 * * *$ & 0.6371 & $0.1748 * * *$ & 1.8322 & $0.2536 * * *$ \\
\hline$\hat{\beta}_{2}$ & -0.7437 & $-0.2714 * * *$ & -2.3012 & 0.0144 & -4.4798 & -0.0579 & 1.2972 & -0.1019 \\
\hline$\hat{\beta}_{3}$ & 0.0797 & 0.0066 & -4.2550 & -0.1535 & 6.7402 & -0.0258 & -0.9497 & 0.0028 \\
\hline$\hat{\beta}_{4}$ & 0.0473 & $-0.5627 * * *$ & -4.5745 & -0.1178 & $-8.6340 *$ & 0.0413 & -1.5334 & -0.0831 \\
\hline$\hat{\beta}_{5}$ & 2.0896 & $0.3286^{* * *}$ & 4.1240 & 0.0235 & -0.9478 & $-0.4212 * * *$ & 0.1692 & $-0.2251 * * *$ \\
\hline$R^{2}$ & $14.6 \%$ & $52.4 \%$ & $53.3 \%$ & $12.0 \%$ & $15.9 \%$ & $23.1 \%$ & $17.5 \%$ & $18.5 \%$ \\
\hline
\end{tabular}

Several diagnostic tools may be applied to the estimated equations to look for specification problems in the models. Firstly autocorrelation is tested for using (i) residual cross-correlograms and (ii) Lagrange Multiplier (LM) tests. The residual cross-correlograms report estimated correlations $\hat{\rho}\left(\varepsilon_{1 t} ; \varepsilon_{1 t-z}\right), \quad \hat{\rho}\left(\varepsilon_{2 t} ; \varepsilon_{2 t-z}\right)$, $\hat{\rho}\left(\varepsilon_{1 t} ; \varepsilon_{2 t-z}\right)$ and $\hat{\rho}\left(\varepsilon_{2 t} ; \varepsilon_{1 t-z}\right)$ for lag lengths up to order $z$ where significance implies autocorrelated residuals.

These results (not shown) fail to indicate autocorrelation in the residuals of all models, with significant correlations occurring very rarely and only at high lag lengths. A further corroborating test employs Lagrange Multipliers and represent a multivariate generalization of the univariate LM test (Johansson, 1995) where the residual $\varepsilon_{t}$ is regressed against the test equation and lagged error terms $\varepsilon_{t-z}$. Again these tests (not shown) fail to find evidence of autocorrelation at

In addition to residual tests the stability of the estimated equations is important. To verify that the following models are stable we note that a VAR(p) model may be 
written in terms of a VAR(1).

$$
\xi_{t}=\mu+\Gamma \xi_{t-1}+v_{t}
$$

where $\xi=\left[\begin{array}{c}Y_{t} \\ \vdots \\ Y_{t-p+1}\end{array}\right], \xi=\left[\begin{array}{c}\mu \\ \vdots \\ 0\end{array}\right], \Gamma=\left[\begin{array}{cccc}\Theta_{1} & \Theta_{1} & \ldots & \Theta_{p} \\ I & 0 & 0 & 0 \\ \vdots & I & 0 & \vdots \\ 0 & 0 & I & 0\end{array}\right]$ and $v_{t}=\left[\begin{array}{c}\varepsilon_{t} \\ \vdots \\ 0\end{array}\right]$.

The VAR will be stable if the eigenvalues of $\Gamma$ lie inside the unit circle (i.e. solutions to $|\Gamma-\lambda I|=0$ have moduli less than one. Applying this technique for the specified systems of equations shows that the four VAR regressions are all stable.

As with any VAR specification it is of interest to examine the direction of causality within the estimated model. The standard way to investigate this is with Granger tests of forecastability, where if variable $x$ is useful for forecasting future values of variable $y$ then $x$ is said to Granger Cause $y$. This involves testing the validity of restriction $\beta_{1 j}=0$ for $j=1 \ldots p$ for the equation governing the series $\Delta G D P_{t}$ and $\alpha_{2 j}=0$, $j=1 \ldots p$ for the equation governing $\Delta T o T_{t}$. If the first set of restrictions holds, then $\triangle G D P_{t}$ is not dependent on lagged values of $\triangle T o T$ once lagged values of $\triangle G D P$ have been controlled for.

In this case there is no evidence of $\triangle T o T$ Granger Causing $\triangle G D P$ as earlier fluctuations in $\triangle T o T$ have no predictive power over $\triangle G D P$. If the second set of restrictions hold, the same conclusion can be drawn with the variables reversed. However if either set of restrictions are rejected by the data this indicates that the history of one series has predictive power over the future values of the other, with the direction implied by the set of restrictions that were rejected.

Granger Causality tests are applied for each VAR specification where the test statistic follows a Chi-Square distribution with $k$ degrees of freedom. The results are reported in Table 5 where the tests are ordered by dependent variable. 
Table 5. VAR Granger Causality Tests for CEAEs, 1980-2011

\begin{tabular}{c|cc|cc|cc|cc}
\hline \hline & \multicolumn{2}{|l|}{ Australia } & \multicolumn{2}{|l|}{ Canada } & & \multicolumn{2}{l}{ New Zealand } & \multicolumn{2}{l}{ Norway } & \\
\hline DV & $\Delta G D P$ & $\Delta$ ToT & $\Delta G D P$ & $\Delta T o T$ & $\Delta G D P$ & $\Delta T o T$ & $\Delta G D P$ & $\Delta$ ToT \\
\hline \hline$X^{2}$ & 1.9692 & 7.4241 & 26.057 & 1.2642 & 4.4665 & 7.3942 & 3.3429 & 6.1306 \\
$P$ & 0.8534 & 0.1910 & 0.0001 & 0.9386 & 0.4844 & 0.1929 & 0.6473 & 0.2937 \\
\hline
\end{tabular}

Note: The second row gives the dependent variable in each test equation, the third row gives the appropriate Chi-Square test statistic and the fourth row contains the p-value of the joint test.

The first column containing figures in Table 5 indicates that the elimination of lagged values of $\Delta T o T$ does not significantly affect the ability of the model to forecast $\triangle G D P$ and hence we conclude that there is no Granger Causality running from $\Delta T o T$ to $\triangle G D P$ for Australia. Extending this interpretation to the rest of the results in Table 5 shows no evidence of significant Granger Causality running either way between the series with the exception of from $\triangle T o T$ to $\triangle G D P$ for Canada. This is in line with our pervious observation of statistical significance in the first lag of Canada's GDP equation.

An intuitive method for depicting the results implied by the coefficient estimates in Table 4 is with the use of Impulse Response Functions (IRFs). We assume that an estimated system has converged to equilibrium and proceed by subjecting each variable (in isolation) to an impulse of a single standard deviation. The response of the system to this shock is then depicted with an adjustment path over time. As we are primarily interested in the behaviour of changes in GDP with respect to the Terms of Trade we will only present graphs showing the response of output with respect to this type of impulse. These are reported below in Figure 4. 
Figure 4. IRF Functions $\triangle G D P$ to $\Delta T o T$

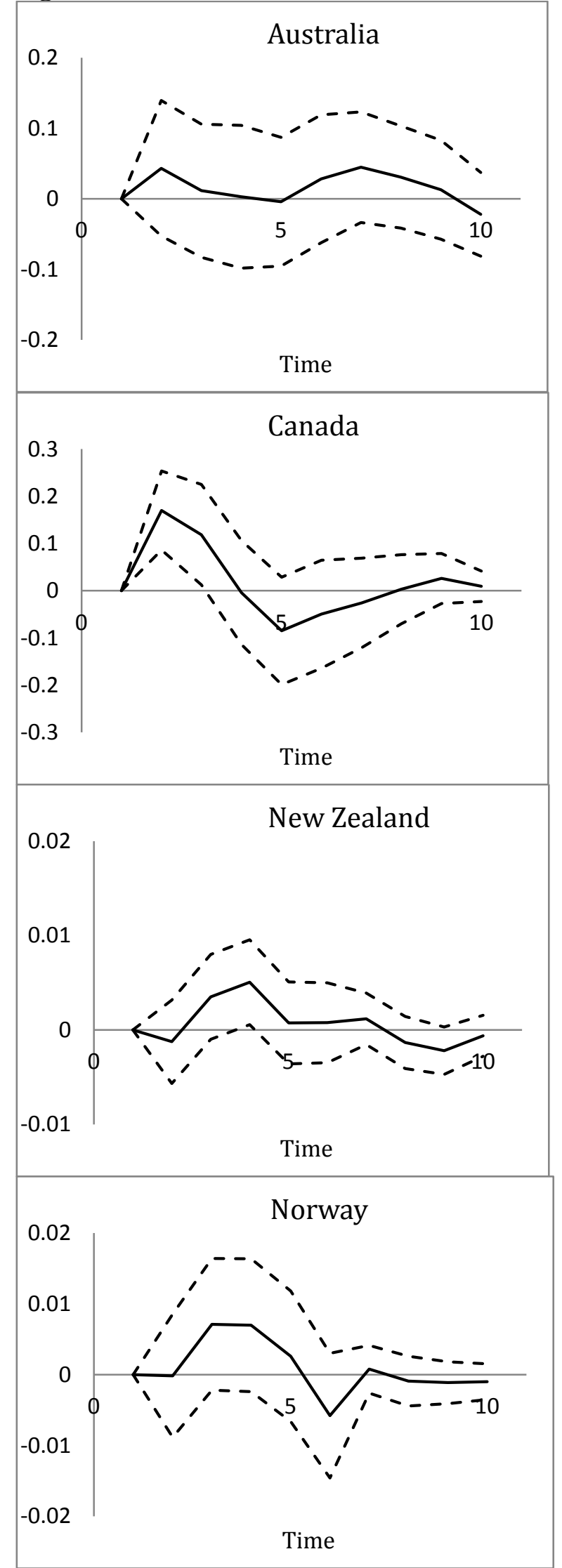

Note: The solid lines show the adjustment paths of $\triangle G D P$ from a one S.D. shock to $\Delta T o T$ for each country. The dotted lines represent a confidence interval based upon two asymptotically determined standard errors. 
All adjustment paths show that the impact of a temporary increase of ToT to the changes in GDP. The adjustment path for Australia is estimated as mostly positive changes over 10 time periods however the magnitude of this effect is small relative to the error bars included in the diagram. The same is true for both New Zealand and Norway which also suggest positive but insignificant movements. The exception to these cases comes from the Canadian data where we estimate that an impulse to ToT coincides with significant positive changes to output two and three quarters later. However these changes are estimated to turn negative after four quarters although the magnitudes are not large enough to be significant.

\section{Testing the Relationship between the ToT and TBs in CEAEs}

As well as examining the dynamic impact of the ToT on GDP, we are also interested in its impact on the variable TB. The same econometric techniques are used for this problem as in the previous section however we will replace the endogenous variable $\Delta G D P_{t}$ with $T B$. Again lag length criteria are used to determine the optimal value of $p$ which we fix across the four countries for the sake of uniformity. Although there is some inconsistence between (i) the recommended lengths of various criteria and (ii) cross national differences, we again settle on a total of five lags. The parameter estimates of the VAR models are presented in Table 6 where the alpha parameters denote coefficients on the Trade Balance and the beta parameters remain the coefficients of the Terms of Trade.

Similar to the parameter estimates in Table 4 ToT appears to have little short run impact upon changes in the Trade Balance. In Australia and Norway there is some evidence of this effect with a significant fourth lag in the former case and first lag in the Norwegian case. However no other lags are significant for these countries and none are significant for Canada or New Zealand. 
Table 6. VAR Coefficients for CEAEs, 1980-2011

\begin{tabular}{|c|c|c|c|c|c|c|c|c|}
\hline & \multicolumn{2}{|l|}{ Australia } & \multicolumn{2}{|l|}{ Canada } & \multicolumn{2}{|c|}{ New Zealand } & \multicolumn{2}{|l|}{ Norway } \\
\hline Lag & $T B$ & $\Delta T o T$ & $T B$ & $\Delta T o T$ & $T B$ & $\Delta T o T$ & $T B$ & $\Delta T o T$ \\
\hline$\overline{\bar{\delta}}$ & $-0.0025 * * *$ & -0.0023 & 0.0015 & -0.0004 & 0.0019 & 0.0037 & $0.0079 *$ & -0.0011 \\
\hline$\hat{\alpha}_{1}$ & 0.0246 & 0.6276 & $1.0375^{* * *}$ & -0.0646 & $0.6264 * * *$ & -0.1354 & $0.7960 * * *$ & 0.3019 \\
\hline$\hat{\alpha}_{2}$ & $-0.0025^{* *}$ & -0.2266 & -0.1272 & -0.1867 & 0.0832 & 0.0125 & -0.1077 & 0.0526 \\
\hline$\hat{\alpha}_{3}$ & -0.0169 & 0.0909 & 0.0433 & 0.0497 & 0.1116 & 0.1334 & -0.0022 & -0.2173 \\
\hline$\hat{\alpha}_{4}$ & -0.0752 & -0.6321 & -0.0906 & 0.3615 & -0.0502 & $0.4463 * *$ & $0.3633 * * *$ & -0.2483 \\
\hline$\hat{\alpha}_{5}$ & 0.0411 & 0.3406 & 0.0608 & -0.1060 & -0.0091 & $-0.5304 * *$ & -0.1470 & 0.1819 \\
\hline$\hat{\beta}_{1}$ & 0.9293 & $-0.6735^{* * *}$ & 0.0647 & $0.2485 * *$ & -0.0168 & $0.2064 * *$ & $0.1785^{* * *}$ & $0.1940^{*}$ \\
\hline$\hat{\beta}_{2}$ & 0.1427 & $-0.0025 * *$ & -0.0265 & 0.0566 & -0.0234 & -0.0513 & 0.0689 & -0.1596 \\
\hline$\hat{\beta}_{3}$ & -0.2754 & -0.0366 & -0.0207 & -0.1245 & -0.0825 & -0.0548 & 0.0731 & -0.0393 \\
\hline$\hat{\beta}_{4}$ & $0.0565^{* * *}$ & $0.9484 * * *$ & -0.0537 & -0.1216 & -0.0130 & 0.0435 & -0.0595 & -0.0554 \\
\hline$\hat{\beta}_{5}$ & $-0.0675^{*}$ & $-0.6402 * * *$ & $0.0977^{*}$ & 0.0321 & 0.0056 & $-0.4226 * * *$ & -0.0016 & $-0.2032 * * *$ \\
\hline$R^{2}$ & $52.4 \%$ & $79.6 \%$ & $87.2 \%$ & $14.9 \%$ & $52.7 \%$ & $27.4 \%$ & $86.2 \%$ & $19.0 \%$ \\
\hline
\end{tabular}

Correlograms and LM tests indicate that the residuals are generally appropriately free of autocorrelation. In some cases we find slight evidence of autocorrelation Further the eigenvalues of the tests indicate that the regressions are stable in all cases.

Granger causality tests are presented in Table 7

Table 7. VAR Granger Causality Tests for CEAEs, 1980-2011

\begin{tabular}{|c|c|c|c|c|c|c|c|c|}
\hline & Australia & & Canada & & New Zeal & & Norway & \\
\hline DV & $T B$ & $\Delta T o T$ & $T B$ & $\Delta T o T$ & $T B$ & $\Delta T o T$ & $T B$ & $\Delta T o T$ \\
\hline$X^{2}$ & 18.95228 & 7.239927 & 6.297017 & 4.901727 & 3.398348 & 7.801846 & 18.63263 & 6.849301 \\
\hline$P$ & 0.0020 & 0.2034 & 0.2784 & 0.4280 & 0.6388 & 0.1675 & 0.0022 & 0.2321 \\
\hline
\end{tabular}

Note: The second row gives the dependent variable in each test equation, the third row gives the appropriate Chi-Square test statistic and the fourth row contains the p-value of the joint test.

Again the results indicate that significant Granger Causality runs from $\triangle T o T$ to $T B$ in Australia and Norway but not Canada or New Zealand. In no case did the causality run the opposite direction.

The impulse response functions are given in Figure 5 and corroborate the evidence in Tables 6 and 7. 
Figure 5. IRF Functions $T B$ to $\Delta T o T$

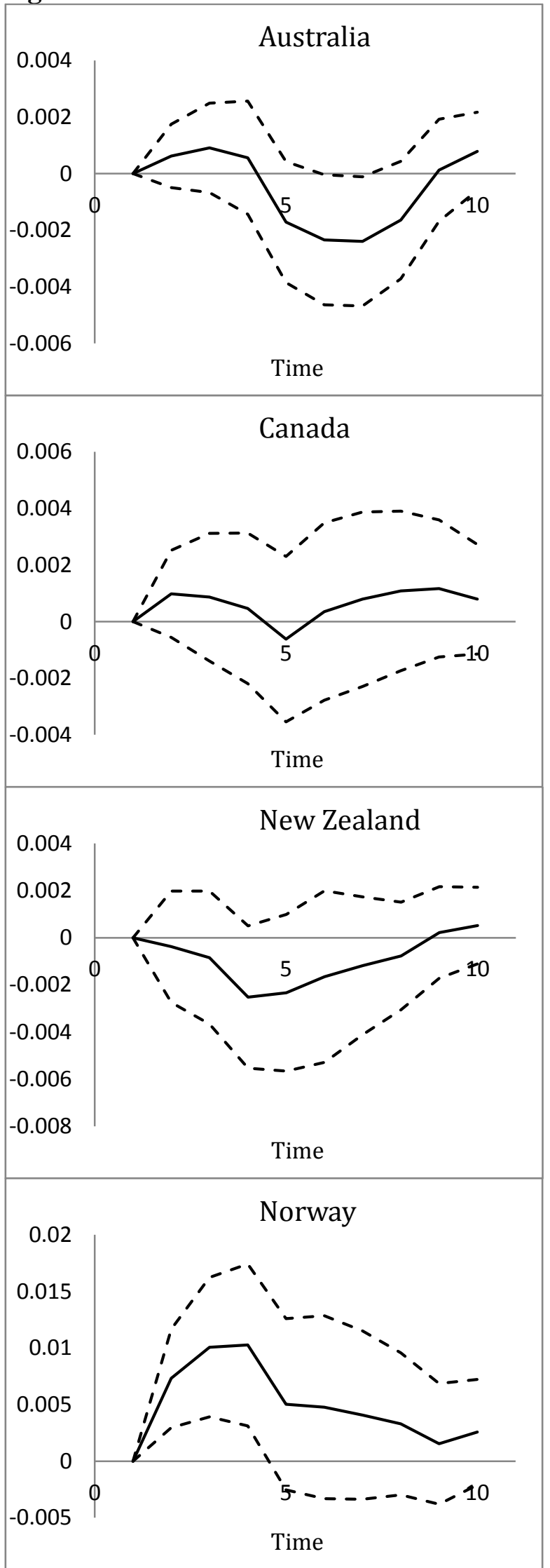

Note: The solid lines show the adjustment paths of $\triangle G D P$ from a one S.D. shock to $T B$ for each country. The dotted lines represent a confidence interval based upon two asymptotically determined standard errors. 
Results from Figure 5 reveal the corresponding adjustment paths of TB from an impulse to ToT. For Australia we see the impulse increasing then decreasing the trade balance over eight quarters although there is no strong statistical significance in either case. Similarly the results for Canada and New Zealand show little evidence of an impulse to the ToT impacting upon trade balances. Conversely Norway shows the impulse having a significant positive effect that is increasing for the first three to four periods and declining thereafter.

\section{Conclusion}

This paper has proposed an alternative framework for interpreting the impact of a rise in world commodity prices on a commodity exporter's output, expenditure and trade balance. The major point of difference between this framework and the standard Dutch disease approach is that it examines the impact of commodity price changes via the relative price of commodities to other goods and services, or the terms of trade, rather than via the relative price of tradables to non-tradables, or real exchange rate. This alternative perspective has yielded the following key results.

First, a boost in the terms of trade will change the composition, but not level of national production, as labor moves from the non-commodity sector to the commodity sector. At the same time however, industry restructuring is accompanied by a rise in national expenditure and macroeconomic welfare due to the income effect stemming from the terms of trade improvement. Hence, the negative effects of industry restructuring are counterbalanced by the positive effect of higher expenditure. Second, a sharp rise in prices received for commodity exports does not unambiguously boost net exports since income and substitution effects simultaneously raise imports.

With application to the major commodity exporting advanced economies (Australia, Canada, New Zealand and Norway), the econometric analysis provides broad support for this approach. Specifically, the results show that, except for Canada, no Granger causality runs from the terms of trade to GDP. Moreover, terms of trade movements driven by commodity price swings have no significant short run impact on GDP in these economies. As implied by the theory, causality may or may not run from the terms of trade to the trade balance, or net exports. While there is evidence of 
causality between the terms of trade and net exports for Australia and Norway, this is not the case for Canada and New Zealand. Again consistent with the alternative theoretical perspective, somewhat counter-intuitively there is little evidence of any strong positive relationship between terms of trade fluctuations and net exports in these economies. 


\section{References}

Adenauer, I., and Vagassky, L. (1998) "Aid and the Real Exchange Rate: Dutch Disease Effects in African Countries" Intereconomics, 33 (4), 177-185.

Bruno, M. and Sachs, J. (1982) "Energy and Resource Allocation: A Dynamic Model of the Dutch Disease" Review of Economic Studies 49(5), 845-859.

Buiter, W.H. and D.D Purvis (1983) "Oil, Disinflation and Export Competitiveness: a Model of the Dutch Disease" in : J.S.Bhandari and B.H. Putnam, eds., Economic Interdependence and Flexible Exchange Rates (MIT Press, Cambridge, MA)

Corden, W. (1984) "Booming Sector and Dutch Disease Economics: Survey and Consolidation" Oxford Economic Papers, 36(3), 359-380.

Corden, W. and Neary, J. (1982) "Booming Sector and De-industrialization in a Small Open Economy” Economic Journal, 825-848.

Deaton, A. and Muellbauer, J. (1980) Economics and Consumer Behavior, Cambridge University Press, Cambridge, UK.

Edwards, S., and Aoki, M. (1983) "Oil Export Boom and Dutch-Disease: a Dynamic Analysis" Resources and Energy, 5 (3), 219-242.

Enders, K. and Herberg, H. (1983) "The Dutch Disease: Causes, Consequences, Cures and Calmatives" Weltwertschaftliches Archiv 119(3), 473-497.

Forsyth, P.J. and Kay, J. (1980) "The Economic Implications of North Sea Oil Revenues” Fiscal Studies 1 (July), 1-28.

Forsyth, P. J. and Kay, J. (1981) "Oil Revenues and Manufacturing Output", Fiscal Studies 2 (July), 9-17.

Frankel, J. (2012) "Natural Resource Curse: A Survey of the Literature" in Arezki, R., Patillo, C. and Quintyn, M. (eds) Commodity Prices and Inclusive Growth in Low Income Countries International Monetary Fund, Washington DC.

Gregory, R. (1976) "Some Implications of the Growth of the Mineral Sector" Australian Journal of Agricultural Economics 20 (August), 71-91.

Harberger, A. (1983) "Dutch Disease - Who Much Sickness, How Much Boom?" Resources and Energy 5, 1-20.

International Monetary Fund Primary Commodity Price Tables www.imf.org/external/np/res/commod/index.aspx

International Monetary Fund (2012) World Economic Outlook, Chapter 4, May, Washington DC.

International Monetary Fund (2011) World Economic Outlook, Chapter 3, September, 
Washington DC.

Kaminsky, G. (2009) “Terms of Trade Shocks and Fiscal Cycles” NBER Working Paper 15780.

Lederman, D. and Maloney, W. (2007) "Natural Resources, Neither Curse Nor Destiny" Stanford University Press and World Bank, Washington DC.

McKinnon, R. (1976) "International Transfers and Non-traded Commodities: The Adjustment Problem”, in Leipziger, D.M. (ed.), The International Monetary System and the Developing Nations, Washington, D.C.: Agency for International Development.

Salter, W. (1959) "Internal and External Balance: The Role of Price and Expenditure Effects" Economic Record 35, 226-238.

Stoeckel, A. (1979) "Some Equilibrium Effects of Mining Growth on the Economy" Australian Journal of Agricultural Economics 23 (2), 1-22.

Swan, T. (1960) "Economic Control in a Dependent Economy" Economic Record, 36, 51-66.

Torvik, R. (2001) "Learning by Doing and the Dutch Disease" European Economic Review, 45 (2), 285-306.

Usui, N. (1998) "Dutch Disease and Policy Adjustments to the Oil Boom: a Comparative Study of Indonesia and Mexico," Resources Policy, 23 (4), 151-162.

Van der Ploeg, F. (2011) "Natural Resources: Curse or Blessing?" Journal of Economic Literature, 49 (2), 366-420.

Van Wijnbergen, S. (1984) “The 'Dutch Disease': A Disease After All?" Economic Journal, 94 (373), 41-55.

Younger, S. (1992) "Aid and Dutch Disease: Macroecnomic Management When Everybody Loves You” World Development, Vol.20 No. 111587-97. 